\title{
Genetic expression of an amyloid peptide fragment and analysis of formylated products
}

Article

Accepted Version

Cheng, G., Krasel, C., Zhou, H. G., Chappell, D. and Hamley, I. W. (2011) Genetic expression of an amyloid peptide fragment and analysis of formylated products. Organic Letters, 13 (10). pp. 2572-2575. ISSN 1523-7060 doi: https://doi.org/10.1021/ol1028145 Available at https://centaur.reading.ac.uk/20399/

It is advisable to refer to the publisher's version if you intend to cite from the work. See Guidance on citing.

To link to this article DOI: http://dx.doi.org/10.1021/ol1028145

Publisher: The American Chemical Society

All outputs in CentAUR are protected by Intellectual Property Rights law, including copyright law. Copyright and IPR is retained by the creators or other copyright holders. Terms and conditions for use of this material are defined in the End User Agreement.

www.reading.ac.uk/centaur 
Central Archive at the University of Reading

Reading's research outputs online 


\title{
Genetic Expression of an Amyloid Peptide Fragment and Analysis of Formylated Products
}

\author{
G. Cheng, C. Krasel, ${ }^{\dagger}$ H. G. Zhou, ${ }^{\dagger}$ D. Chappell, I. W. Hamley* \\ School of Chemistry, Food Science and Pharmacy, University of Reading, \\ Whiteknights, Reading RG6 6AD, UK \\ ${ }^{\dagger}$ Currently at Institut für Pharmakologie \& Toxikologie, Karl-von-Frisch-Strasse 1 \\ 35041 Marburg, Germany \\ *I.W.Hamley@reading.ac.uk. Also at Diamond Light Source, Harwell Science and \\ Innovation Campus, Chilton, Didcot OX11 ODE, UK
}

Received Date (will be automatically inserted after manuscript is accepted)

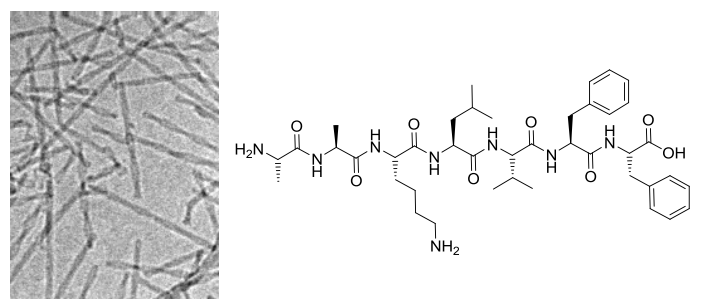

The model amyloid peptide AAKLVFF was expressed as a His-tagged fusion protein with the immunoglobulinbinding domain B1 of streptococcal protein G (GB1), a small (56 residues), stable, single-domain protein. We show that expression of this model amyloid peptide is possible, and is not hindered by aggregation. Formylation side reactions during the $\mathrm{CNBr}$ cleavage are investigated via synthesis of selectively formylated peptides.

Expression of proteins using recombinant DNA methods is now ubiquitous, however expression of amyloid-forming proteins is potentially complicated by aggregation of the peptide during or after expression. Indeed, short amyloid forming segments can drive a nonfibrillizing protein into the amyloid state. This was shown by Teng and Eisenberg who demonstrated that when 6-8 residue fragments from amyloid-forming human proteins tau, $\alpha$-synuclein, $\operatorname{PrP}$ prion and amyloid $\beta(\mathrm{A} \beta)$ were inserted into a region of the enzyme RNase A amyloid formation occured. ${ }^{1}$ Baxa et al. showed that fusion of the Ure2p prion protein with various proteins led to amyloid formation. ${ }^{2}$ The functions of the proteins (barnase, carbonic anhydrase, glutathione S-transferase and green 
fluorescent protein) were not substantially influenced showing that they retained their native structures. Amyloid fibrils have been used as scaffolds to present proteins such as cytochrome $\mathrm{c}$, which retains its function on fibrils formed from a fusion construct with the amyloid forming SH3 domain. ${ }^{3}$ It is therefore of great interest to determine methods by which amyloid-forming short peptides can be expressed without driving amyloid assembly of the host protein in the fusion construct.

The Hamley group have recently investigated the selfassembly of peptide $\mathrm{NH}_{2}$-AAKLVFF-COOH in detail. ${ }^{4-7}$ This peptide is based on sequence $A \beta(16-20)$, KLVFF, from the amyloid $\beta$ peptide, extended at the $\mathrm{N}$ terminus with two hydrophobic alanine residues. In water at sufficiently high concentration, this peptide forms twisted fibrils (as observed by TEM and cryo-TEM), ${ }^{4,6,7}$ whereas in methanol it forms nanotubes. ${ }^{5-7}$ Both these structures have also been reported for the related peptide $A \beta(16-22)$, KLVFFAE, by varying $\mathrm{pH}$ in aqueous solution. ${ }^{8,9}$ The formation of $\beta$-sheet structures in both solvents has been confirmed by FTIR, x-ray diffraction experiments in solution and circular dichroism (CD) spectroscopy on dried films. ${ }^{4-7}$ In dilute solution, the CD spectra reveal the absence of $\beta$-sheet ordering but instead show features of a disordered conformation with a possible contribution from aromatic stacking interactions resulting from the phenylalanine residues. Solution NMR experiments were used to examine the solubility of the peptide in the two solvents, and to determine the critical aggregation concentration. $^{7}$

In the present paper, we report on the expression of AAKLVFF using a recombinant protein. This work was motivated by the desire to explore the synthesis of the peptide on a larger scale using appropriate hosts (eg. bacteria) and this work provides proof-of-concept of this. It is noted that the cyanogen bromide cleavage step leads to formylated peptide, and the nature of the formylated product was investigated in detail via synthesis of AAKLVFF formylated either just at the $\mathrm{N}$ terminus or additionally at the $\mathrm{K}$ residue. This indicates that $\mathrm{CNBr}$ produces a peptide with backbone formylation at the $\mathrm{N}$ terminus. Formylation at the $\varepsilon$-amino group in lysine was achieved by blocking the peptide $\mathrm{N}$ terminus in azidoAAKLVFF. Formic acid /acetic anhydride did not give a formylated product, however, successful formylation was achieved with $p$-nitrophenol in a borate buffer $(\mathrm{pH}=10) /$ acetonitrile $(1: 1)$. Formylation of peptides and proteins has been investigated previously, ${ }^{10-12}$ however we are not aware of prior reports on this in the preparation of recombinant amyloid-type peptides.

We used the GB1 fusion protein domain to express the model amyloid forming peptide AAKLVFF. Theoretically, cleaving the GB1-AAKLVFF fusion protein sequence by $\mathrm{CNBr}$ leads to sequences shown in Table 1, based on the UniProt Knowledgebase (Swiss-
Prot and TrEMBL). ${ }^{13}$ The corresponding peptide masses $\left([\mathrm{M}+\mathrm{H}]^{+}\right)$from the sequence are also shown in Table 1.

\begin{tabular}{|ll|}
\hline mass & \multicolumn{1}{c|}{ peptide sequence } \\
& HIAAGACCTTTACAGTTACT \\
6024.4586 & GAACATATGGCGGCGAAACT \\
& GGTGTTCTTTTAAGGATCCK \\
& TFTVTEHM \\
& GGTACCATGGGCAGCAGCCA \\
5229.8631 & TCATCATCATCATCACACTT \\
& ACAAATTAATCCTTAATGGT M \\
795.4763 & AAKLVFF \\
\hline
\end{tabular}

Table 1 Theoretical analysis of peptide masses $\left([\mathrm{M}+\mathrm{H}]^{+}\right)$ cleaved from GB1-AAKLVFF

The ESI-MS spectrum of the product obtained from RP-HPLC was compared with that of synthetic AAKLVFF, revealing the $[\mathrm{M}+\mathrm{H}]^{+}$peak 795.4767 (genetic) / 795.4765 (synthetic), (calc. 795.4771) and the doubly protonated peak $[\mathrm{M}+2 \mathrm{H}]^{+}$at 398.2419 (genetic) / 398.2418 (synthetic) (calc. 398.2426) in both spectra (SI Fig.1). In addition, fragmention analysis confirmed the sequence AAKLVFF. However, an ion at $\mathrm{m} / \mathrm{z} 851.6071$ was also detected in the mass spectrum of the cleaved sequence AAKLVFF corresponding to an additional mass of $56 \mathrm{Da}$ which is consistent with formylation of both primary amines by the formic acid.

In order to investigate the formation of formylated byproducts in more detail, formylation of a sample of AAKLVFF in $98 \%$ formic acid was conducted in the presence of acetic anhydride ${ }^{10}$ in addition to a control experiment which consisted of the formylation of synthetic AAKLVFF in $70 \%$ formic acid with an excess of cyanogen bromide. The experiments were both monitored by RP-HPLC and after 6 hours the formylation using $98 \%$ formic acid displayed a new peak at $10.03 \mathrm{~min}$ (Peptide I, Scheme 1) whereas, in the control experiment, a new peak was observed at $10.59 \min$ after 7 days (Peptide II) as shown in SI Fig 2.

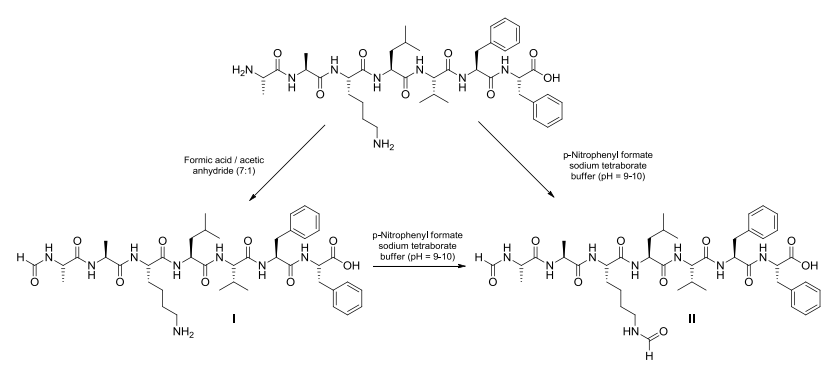

Scheme 1. Formylation of peptide AAKLVFF to give peptides I and II.

Analysis of the fragmentation peaks in the mass spectrum of peptide I revealed the $[\mathrm{M}+\mathrm{H}]^{+}$peak 823.4708 
(calc. 823.4720) indicating that it was the monoformylated product, formylated at the backbone $\mathrm{N}$ terminus (Scheme 1).

In order to investigate further the single selective formylation reaction, the peptide azido-AAKLVFF III blocked at the N-terminus with 3-azidopropanoic acid which contained only the primary amine on the lysine side-chain was synthesized (Scheme 2). In this case, formylation was not observed in $98 \%$ formic acid /acetic anhydride, however, successful formylation to produce peptide IV was achieved based on a method reported by Dempsey, ${ }^{10}$ using $p$-nitrophenol in a borate buffer $(\mathrm{pH}=10) /$ acetonitrile mixture (1:1) (Scheme 2). As a consequence, formylation of peptide AAKLVFF was attempted using these same conditions and the isolated product displayed an identical retention time $\left(t_{R}\right)$ with peptide II. The ESI-MS spectrum of the product showed the $[\mathrm{M}+\mathrm{H}]^{+}$ion at 851.4673 , thereby confirming bisformylation, both on the backbone and on the lysine sidechain (calc. 851.4669).

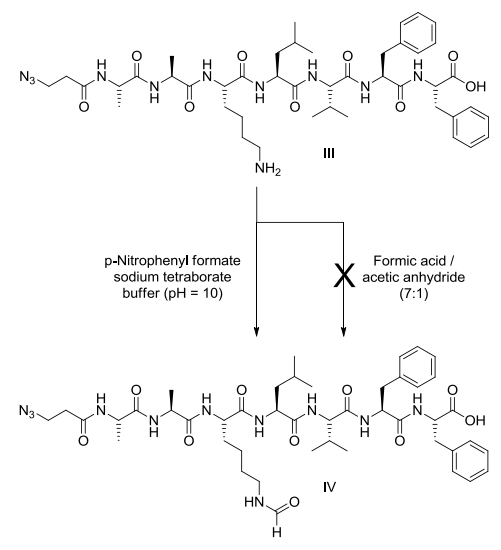

Scheme 2. Formylation of peptide azido-AAKLVFF (III) to produce peptide IV.

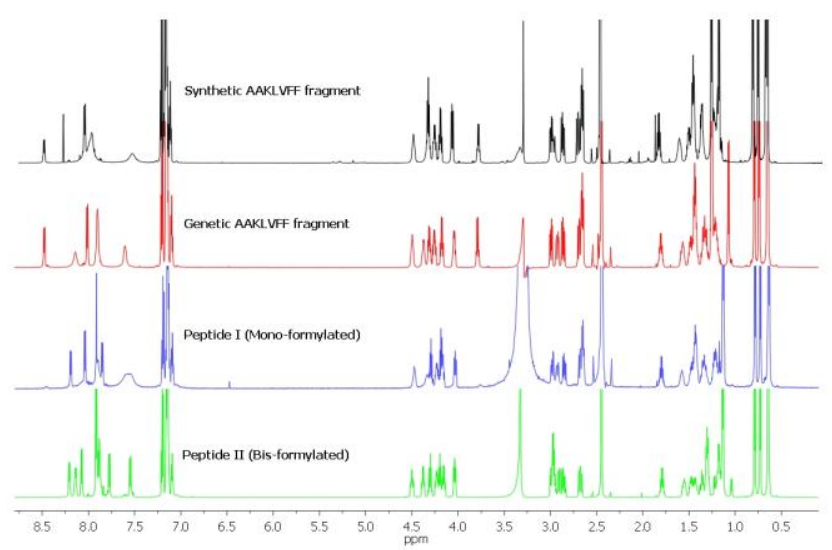

Figure 1. Comparison of ${ }^{1} \mathrm{H}-\mathrm{NMR}\left(\mathrm{DMSO}-\mathrm{d}_{6}\right)$ of genetic and synthetic AAKLVFF fragments, Peptide I (formylation on backbone) and Peptide II (formylation on backbone and lysine side chain).
The genetic AAKLVFF was isolated from its monoformylated (Peptide I) and bis-formylated (Peptide II) analogues following repeated semi-preparative HPLC (SI Fig. 2b). All of the ${ }^{1} \mathrm{H}-\mathrm{NMR}$ data have been analysed (Figure 1), and are reported in the experimental section (Supporting Information).

The self-assembly of peptides I, II and III was studied using FTIR spectroscopy, circular dichroism (CD) and cryogenic-transmission electron microscopy (cryo-TEM). We have previously reported in detail on the selfassembly of synthetic AAKLVFF in water, using these techniques. Fig. 2 shows representative cryo-TEM images of these peptides, showing self-assembly into fibrils. Due to insolubility in water, peptide II was dissolved in a 1:1 water/acetonitrile mixture. Peptide I exhibits short rigid fibrils, which at high magnification can be seen to be twisted. In contrast, peptide II shows longer, less straight fibrils which at higher magnification do not, in general, show twisting. The difference in morphology of these samples highlights the influence of packing and electrostatic interactions on the intermolecular stacking of the $\beta$-sheets. Peptide III formed a very dense network of extended fibrils as shown in Fig.2c. It was also necessary to dilute this sample (compared to conditions used for I and II) in order to image the fibrillar network by cryoTEM. The presence of the azido group appears to enhance fibrillisation of AAKLVFF, possibly due to enhanced hydrophobic interactions.

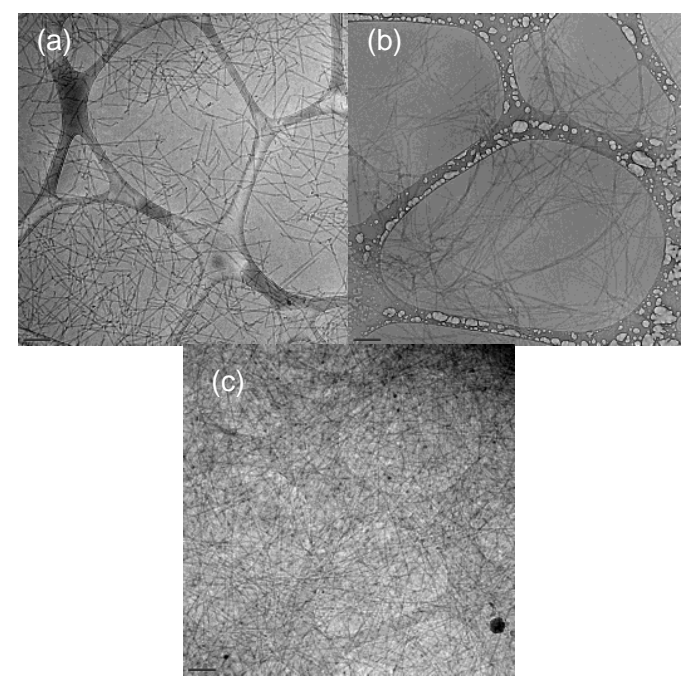

Figure 2. Cryo-TEM images (a) mono-formylated peptide I (2 wt $\%$ in $\mathrm{H}_{2} \mathrm{O}$ ), (b) bis-formylated peptide II (2 wt $\%$ in $1: 1$ $\left.\mathrm{H}_{2} \mathrm{O}: \mathrm{CH}_{3} \mathrm{CN}\right)$, (c) azido-AAKLVFF, peptide III (0.012 wt $\%$ in $\mathrm{H} 2 \mathrm{O}$ ). The scale bars represent $200 \mathrm{~nm}$.

These fibrils are rich in $\beta$-sheet as shown by the representative FTIR spectrum for peptide III in Fig.3a (and our previous extensive characterization of 
$\mathrm{AAKLVFF}^{4,6,7}$ ). FTIR spectroscopy in the amide I region provides information on secondary structure. Fig.3a shows a peak at $1625 \mathrm{~cm}^{-1}$ associated with $\beta$-sheet and a smaller peak at $1672 \mathrm{~cm}^{-1}$ often ascribed to the presence of TFA counterions. ${ }^{14-16}$ The CD spectrum (Fig.3b) measured under the same conditions shows a maximum at around $190 \mathrm{~nm}$ and abroad minimum around $210 \mathrm{~nm}$, also consistent with $\beta$-sheet structure.
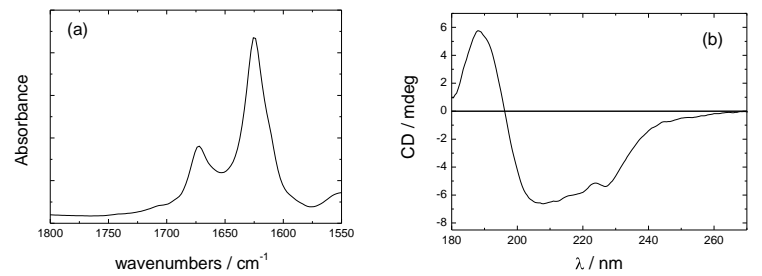

Figure 3. (a) FTIR and (b) CD data for an $0.98 \mathrm{wt} \%$ solution of peptide III in $\mathrm{D}_{2} \mathrm{O}$.

In summary, we have shown that genetic engineering methods can be used to produce a model amyloid peptide. $\mathrm{CNBr}$ cleavage leads to a product that is formylated at the $\mathrm{N}$ terminus and on the lysine $\varepsilon$-amino group. Selfassembly of mono- and bis- formylated AAKLVFF leads to fibrils with distinct structures. A model system with an azido-functionalized $\mathrm{N}$ terminus (blocked for formylation studies) also self-assembles, with a much greater density of fibrils than for the other peptides and with well resolved $\beta$-sheet features in the FTIR and CD spectra. The azido-functionalized peptide is also under investigation as a building block to construct three dimensional chemical structures, e.g. star-type macromolecules or peptide-functionalized hyperbranched molecules, by "click" chemistry.

Acknowledgment This work was supported by EPSRC grant EP/F048114/1 to IWH that supported GC and EPSRC Platform grant EP/G026203/1 that supported DC. We thank Dr Valeria Castelletto and Ms Claire Moulton for assistance with FTIR and CD spectroscopy. We are grateful to Steve Furzeland and Derek Atkins (Unilever, Colworth, UK) for the cryo-TEM experiments. We thank the University of Reading for the award of a RETF studentship for Mr H.G.Zhou.

Supporting Information Available Experimental methods, Scheme showing DNA sequence of fusion construct used to synthesize GB1-AAKLVFF, electrospray mass spectra, RP-HPLC chromatograms.

\footnotetext{
1. Teng, P. K.; Eisenberg, D. Protein Engineering, Design and Selection 2009, 22, (8), 531-536.

2. Baxa, U.; Speransky, V.; Steven, A. C.; Wickner, R. B. Proc. Natl. Acad. Sci. U. S. A. 2002, 99, (8), 5253-5260.

3. Baldwin, A. J.; Bader, R.; Christodoulou, J.; MacPhee, C. E.; Dobson, C. M.; Barker, P. D. J. Am. Chem. Soc. 2006, 128, (7), 2162-2163.

4. Castelletto, V.; Hamley, I. W.; Harris, P. J. F. Biophys. Chem. 2008, 138, 29-35.
}

5. Krysmann, M. J.; Castelletto, V.; McKendrick, J. M. E.; Hamley , I. W.; Stain, C.; Harris, P. J. F.; King, S. M. Langmuir 2008, 24, 8158-8162.

6. $\quad$ Castelletto, V.; Hamley , I. W.; Harris, P. J. F.; Olsson, U.; Spencer, N. J. Phys. Chem. B 2009, 113, 9978-9987.

7. Hamley, I. W.; Nutt, D. R.; Brown, G. D.; Miravet, J. F.; Escuder, B.; Rodríguez-Llansola, F. J. Phys. Chem. B 2010, 114, 940951.

8. Mehta, A. K.; Lu, K.; Childers, W. S.; Liang, S.; Dong, J.; Snyder, J. P.; Pingali, S. V.; Thiyagarajan, P.; Lynn, D. G. J. Am. Chem. Soc. 2008, 130, 9829-9835.

9. Liang, Y.; Pingali, S. V.; Jogalekar, A. S.; Snyder, J. P.; Thiyagarajan, P.; Lynn, D. G. Biochemistry 2008, 47, (36), 1001810026.

10. Dempsey, C. E. J. Chem. Soc., Perkin Trans. 1 1982, 11, 2625-2629.

11. Goodlett, D. R.; Armstrong, F. B.; Creech, R. J.; van Breemen, R. B. Anal. Biochem. 1990, 186, (1), 116-120.

12. Duewel, H. S.; Honek, J. F. J. Protein Chem. 1998, 17, (4), 337-350.

13. http://expasy.org/tools/peptide-mass.html, In 2010.

14. Pelton, J. T.; McLean, L. R. Anal. Biochem. 2000, 277, $167-$ 176.

15. Gaussier, H.; Morency, H.; Lavoie, M. C.; Subirade, M. Appl. Environ. Microbiol. 2002, 68, (10), 4803-4808.

16. Eker, F.; Griebenow, K.; Schweitzer-Stenner, R. Biochemistry 2004, 43, (22), 6893-6898.

17. Huth, J. R.; Bewley, C. A.; Jackson, B. M.; Hinnebusch, A. G.; Clore, G. M.; Gronenborn, A. M. Protein Science 1997, 6, (11), 2359-2364.

18. Bradford, M. M. Anal. Biochem. 1976, 72, (1-2), 248-254.

19. Choikhet, K.; Glatz, B.; Rozing, G. LC GC Europe 2003, 16.

20. Williams, S. Journal of Chromatography $A$ 2004, 1052, (12), 1-11. 